\title{
LA NUEVA ORIENTACIÓN DEL RÉGIMEN DE SALUD EN COSTA RICA: UN ACERCAMIENTO AL CONTEXTO DE CRISIS INSTITUCIONAL DEL SEGURO SOCIAL TRAS EL 75 ANIVERSARIO DE LA PROMULGACIÓN DE LAS GARANTÍAS SOCIALES
}

\section{THE NEW ORIENTATION OF HEALTH REGIME IN COSTA RICA: AN APPROACH TO THE INSTITUTIONAL CRISIS CONTEXT OF THE SOCIAL INSURANCE AFTER THE 75 TH ANNIVERSARY OF THE SOCIAL WARRANTS PROMULGATION}

Andrés Araya Vargas*

Fecha de recepción: $31 / 07 / 2019$

Fecha de aceptación: 05/09/2019

Resumen: Desde el abordaje de la gestión de la política de salud y su interacción con las demandas de un mercado neoliberal, se esquematiza la evolución del Seguro Social de Costa Rica en materia médica al celebrar el 75 aniversario de la promulgación de las garantías sociales, donde se expone a la Caja Costarricense del Seguro Social como una institución sin fines de lucro que vela por los paradigmas de bienestar social de dicha política. En el análisis se pone a discusión la lógica de bienestar social y su transfiguración acorde a los intereses de funcionarios y de usuarios. De igual manera, se da una reflexión respecto a la apropiación discursiva de la sociedad de esta institución médica y las valoraciones económicas que surgen de ello.

Palabras claves: Seguridad social; servicio de salud; bienestar social; política económica; estudios sociales; Costa Rica.

\begin{abstract}
Since the discussion of the health politics and its interaction with the neoliberal market demands, the projection of the social insurance is performed in the medicine area in Costa Rica after celebrating its 75th Social Warranties promulgation anniversary where the Caja Costarricense del Seguro Social is exposed as an institution without lucrative purposes that looks out for ideologies related to social welfare. In the analysis, the logic of the social welfare and the transfiguration according to their officials and users is discussed. As the same way, a social critic about this medical institution society appropriate discursive and the economic valuations originated from it.
\end{abstract}

Keywords: Social Security; Health Services; Social Wellfare; Economic Policy; Social Studies; Costa Rica.

* Costarricense. Bachiller en Estudios Sociales y Educación Cívica por la Universidad Nacional (UNA), Costa Rica. Actualmente, investigador independiente y estudiante de la Licenciatura Estudios Sociales y Educación Cívica en la UNA, Costa Rica. Correo electrónico: andf3ne@gmail.com 
La nueva orientación del régimen de salud en Costa Rica: un acercamiento al contexto de crisis institucional del Seguro Social tras el 75 aniversario de la promulgación de las garantías sociales

\section{Introducción}

A finales de los años treinta e inicios de los cuarenta, Costa Rica presentó un panorama esperanzador, pues dejaba atrás una de las peores crisis económicas, morales y políticas del siglo XX. En la evolución de dicha crisis, la coyuntura de la Segunda Guerra Mundial marcó el inicio de cambios estructurales que profundizaron las relaciones entre la sociedad y el aparato gubernamental. Aunque para finales de 1940 aún se podían apreciar secuelas, el país inició su recuperación económica y social con la aparición de las políticas sociales denominadas garantías sociales, como pacto entre el Estado y la ciudadanía. Si bien, esta capacidad de organización política demarcó un punto en la historia de la nación bajo la alianza tricéfala calderocomunista, su fundamentación histórica, jurídica y social tiene sus bases en la Carta Magna de Juan sin Tierra de 1215, las políticas de Bismarck (1881) y los pensamientos del socialcristianismo.

Durante la operación de estas garantías, se tuvo el afán por responder a proyectos políticos con perspectivas ideológicas, no siempre consistentes, con el impulso de programas estratégicos para la superación de los principales problemas que azotaban al país. Los diferentes esquemas de la política social, salud, trabajo y educación, en distintas administraciones, dejaron entrever una subordinación de dicha política social a los objetivos de la estabilización y reactivación económica. Es aquí donde se da una mutación de la lógica estatal, fuertemente permeada por la apertura de mercados y los nuevos paradigmas neoliberales que caracterizaron a las diversas administraciones del gobierno central y el accionar ciudadano.

\section{La nueva orientación de la política social de salud}

La prestación de servicios médicos es una rama fuerte dentro de las dinámicas comerciales de cualquier nación. Costa Rica no es una excepción, puesto que desde la inserción de esta actividad en el discurso del Estado benefactor, procuró un fortalecimiento del mismo sistema por más de 75 años. Aunque para la lógica económica neoliberal imperante actual cualquier empresa con tendencia social es poco rentable, puesto que dentro de la lógica de acumulación de capital cualquier inversión debe ver reflejada una salida de ganancia mayor para así asegurar la rentabilidad de la empresa. Al visualizar el gasto público o una empresa estatal bajo este lente económico, sobresale el nulo afán por la usura, debido a la consolidación del bienestar social. Esta demanda agregada en la balanza comercial es para el país su participación en sectores de salud y otros, y por tanto debe tratarse esta 
cobertura médica desde una lógica empresarial. El Estado costarricense apostó por esta inversión en la salud como motor de su actividad económica desde el siglo XX. Méndez (2016), en un comunicado de prensa del Programa del Estado de la Nación del 29 de junio del 2016, argumentó que “...hay 4 instituciones que concentran el 56\% del presupuesto, estas son: la Caja Costarricense del Seguro Social, el Instituto Costarricense de Electricidad, la Refinadora Costarricense de Petróleo y el Ministerio de Educación Pública”. Por tanto, una gran porción de los beneficios e inversiones fiscales del Estado son redirigidos hacia los costos de empresas con carácter social.

En Costa Rica el sistema de salud, en su mayoría, está bajo el mando del Estado y se encuentra dividido en cinco entidades públicas. El más grande referente es la Caja Costarricense del Seguro Social (CCSS). Esta institución se encarga del "aseguramiento de la población y de la provisión de la mayor parte de los servicios de salud brindados en el país" (Rodríguez, 2005, p. 9). El principal objetivo de la reforma económica de los años noventa hizo que la Caja se hiciera cargo de la atención primaria, previamente bajo la tutela del Ministerio de Salud, sumado a esto la atención secundaria y terciaria de la población, como lo ha realizado desde su fundación. Por esta razón buscó reorganizar sus servicios de atención mediante los Equipos Básicos de Atención Integral en Salud (EBAIS) y las áreas de salud, los cuales se encargan de la atención de primer nivel. Respecto al segundo y tercer nivel, se dio mediante los hospitales y las clínicas. En total se "encuentran 29 hospitales, 10 clínicas, 103 áreas de salud y 857 EBAIS” (Rodríguez, 2005, p. 10).

Por su parte, el Ministerio de Salud dejó de proveer servicios primarios de atención, por lo tanto, se enfocó en la función de rector y regulador del mercado de salud costarricense. Asimismo, una nueva tarea del Ministerio fue la vigilancia de la salud, creando una dirección especializada para el cumplimento de esta función. De forma adjunta, una nueva encomienda fue la responsabilidad de promover la investigación científica y la innovación tecnológica en aquellos campos que considere estratégicos desde el punto de vista de la promoción, la prevención y la curación. Este es el ámbito en que menos se ha desarrollado la función de rectoría del Ministerio (Rodríguez, 2005, p. 14). Las otras entidades encargadas del sector salud del país son: el Instituto Nacional de Seguros (INS), el Instituto Costarricense de Acueductos y Alcantarillados (AyA) y la Universidad de Costa Rica (UCR). El INS es una institución a cargo de gestionar los seguros comerciales del país. Por su parte, el AyA se encarga de la provisión del servicio de agua potable y de alcantarillado sanitario con la ayuda de las municipalidades. Por último, la UCR es la encargada de la docencia y la formación de profesionales de la salud desde el ámbito público, así como de la provisión de algunos servicios de atención primaria.

De igual forma, los gobiernos de turno destinaron fondos para la creación de organismos destinados a facilitar la aplicación de nuevas medidas 
La nueva orientación del régimen de salud en Costa Rica: un acercamiento al contexto de crisis institucional del Seguro Social tras el 75 aniversario de la promulgación de las garantías sociales

acordes a las dinámicas económicas y políticas de las últimas décadas del siglo XX. Entre los ejemplares de instituciones o departamentos con tal afán sobresalen “...la Escuela de Servicio Social, el Departamento de Enfermeras Visitadoras y de Servicio Social, el Departamento de Unidades Sanitarias e Higiene Rural y la Dirección General de Asistencia y Protección Social" (Rovira, 1992, p. 286). Estas nuevas tendencias normativas de la salud y garantía social de la época fomentaron una absorción estatal de los antiguos hospitales bananeros y empresas médicas privadas.

\section{Gestión pública ante las modificaciones público-privadas del sector salud}

Para los años finales del milenio, el sistema médico nacional, protagonizado por la CCSS, amalgamó una red de cuido y atención, lo cual dio una evolución a la calidad de vida de la población. No obstante, los nuevos contextos globales enmarcaron un debilitamiento de la inserción estatal en las políticas económicas y en los intereses de corte social. La crisis económica de los primeros años ochenta ha sido interpretada como un signo del fracaso y agotamiento del modelo desarrollista o keynesiano del continente en las décadas previas a 1980. A lo largo de este período, América Latina sufrió un debilitamiento del gasto público tras un desequilibrio en la balanza comercial, el déficit fiscal y diversos problemas políticos. Tal como lo planteó Vargas (2015), las causas de la crisis de 1981 y 1982 fueron básicamente dos. En primer lugar, el agotamiento del modelo económico puesto en práctica a partir de la Segunda Guerra Mundial, con mayor precisión durante el cuarto de siglo que se inicia entre 1950 y 1952 y concluye entre 1975 y 1977 (p. 23). En segundo lugar, la política económica equívoca adoptada para hacerlo frente a los efectos externos desde cambios en las dimensiones políticas, que afectan el ciclo económico. Uno de estos cambios a nivel general en el continente fue la tesis de Ronald Regan o la Reaganomics, "la mejor política es la no política", la cual se interpreta como un retorno al liberalismo de los mercados.

Para muchos académicos y asesores estatales, la solución ante los números rojos de las arcas públicas fue una contracción de su gasto público sustituido por una nueva incorporación del sector privado. Esta liberalización y creciente desregularización del sistema financiero abrió espacio para el potencial capital privado y una eventual instalación de servicios hospitalarios externos a la administración pública. Adjunto a estos comunes denominadores, la instancia del Banco Mundial abogó por tratados de ajustes y reformas de las políticas en el continente orientadas hacia un nuevo paradigma liberal. Fue así como imperó una promoción por el rescate de las economías latinas, a riendas de intereses individuales y la poca o nula participación estatal. El lapso temporal de los ochenta, en América tiene como 
cualidad una hegemonía de prácticas para la estabilización macroeconómica. Desde los Programas de Ajuste Estructural, el Banco Mundial y el FMI reorganizaron las cotas del Estado en la economía y un declive en las políticas sociales. Justo como citó Patricia Olave (1990);

"Desde 1982, el Fondo Monetario Internacional (FMI) y luego el Banco Mundial (BM) han tratado no sólo de asegurar los pagos del crédito externo, sino, además de impulsar readecuaciones productivas volcadas hacia el exterior, acorde a la reestructuración de la economía internacional" (p. 27).

Estos juicios de nuevo orden orbitaron ante los principios de la liberalización económica, una paulatina privatización de la empresa pública -como el caso de la CCSS- y una desregulación de los mercados a manos del Estado. Una reactivación económica fue la estrategia promovida por estos idearios liberales, cuya función era acomodar la estructura de la macroeconomía en función de la inversión extranjera y al amparo desde la jurisdicción estatal.

En el subcontinente latinoamericano, los postulados de ajuste fueron ejecutados según las recomendaciones de estos organismos previamente citados, sin consideración alguna ante las cualidades únicas de cada país. Sin embargo, el caso de Costa Rica difiere de sus homólogos al aplicar las medidas de forma paulatina y filtrada ante las necesidades de la nación y todos sus actores. Cuando entró a regir el Programa de Ajuste I y II a Costa Rica fomentó diversos compromisos que el gobierno debió asumir. Gracias a una operación selectiva y gradual -de lo que fueron en el resto del continente las políticas de shock- el país no sacrificó su compromiso social, a diferencia del resto del continente (Arias y Muñoz, 2007), recurriendo a una acotación de las fuerzas sociales y políticas, donde los efectos visualizados no son inmediatos y existe una resistencia estatal ante la ortodoxia del Consenso de Washington. No obstante, las particularidades heterodoxas -en la metodología- permearon en Costa Rica una promoción de sus indicadores sociales de una forma más efectiva que el resto de la región. Mas toda esta metodología macroeconómica desestabilizó el sistema médico público y sirvió como caldo de cultivo para las empresas de salud privadas para su libre competencia en el territorio nacional.

Ya para 1990, la presión por el consumo entre los grupos medios generó el trato por alcanzar mayores niveles de ingresos y demandas sociales que orbitaron las lógicas de los mercados. El cúmulo de la frustración de las expectativas a que se da lugar fortaleció aún más esa compulsión hacia la obtención del dinero y de los derechos que permitieran a la población acceder a servicios brindados por el Estado y respaldos jurídicos de sus accionares dentro de la sociedad. A la entrada del nuevo milenio, convergieron administraciones públicas con escándalos políticos amparados en reformas de modernización técnica y 
La nueva orientación del régimen de salud en Costa Rica: un acercamiento al contexto de crisis institucional del Seguro Social tras el 75 aniversario de la promulgación de las garantías sociales

administrativa de la empresa pública en la medicina. A partir de 1994 "se realiza una reestructuración orgánica y administrativa que le permite cumplir con su papel normativo y rector, pero que al mismo tiempo, la oriente hacia sus clientes" (BINASS, 1997, p. 15). La principal cualidad de este lapso fue una liberalización y promoción de la autonomía de la institución con el resto del aparato estatal. Gracias a este nuevo paradigma, el sistema de atención de salud pública cuenta con una cobertura mayor en sus instrumentos médicos tabulados en:

“...971 Equipos Básicos de Atención Integral distribuidos en 104 Áreas de Salud y está dividido en tres niveles de atención: Primer nivel: equipos básicos compuestos por médico, auxiliar de enfermería y asistente técnico de atención primaria con apoyo de personal de registros médicos. Segundo nivel: brinda apoyo al primer nivel en laboratorio y gabinete, médicos especialistas u otros profesionales afines (nutrición, psicología, trabajo social, enfermería) a través de clínicas de segundo nivel y hospitales periféricos y regionales. Tercer nivel: compuesto por los hospitales nacionales generales y especializados" (Gallardo, 2010, pp. 20-21).

Desde una reducción de su tamaño empresarial gracias al programa de "movilidad voluntaria" (BINASS, 1997, p. 15) del personal y una nueva norma informática, el servicio fue capacitado para responder a las demandas de los años 2000. No obstante, este nuevo esquema adoptado por la institución de políticas y burocracias renunció ante los orígenes de esta, una medicina social. Para muchos académicos, de todas las esferas públicas y administrativas, en los últimos años de la CCSS, se perdió la sensibilidad de socialismo a costa de las vías tecnológicas y de purgas de oficina. Fue así como muchos de los intentos por reenfocar los objetivos empresariales de la institución de salud concluyeron en negocios discrepantes con pérdidas económicas. Caso hegemónico fue el del exmandatario Rafael Ángel Calderón Fournier, acusado por cargos de corrupción y tráfico de influencias durante su administración del año 1990 a 1994. El juicio llevado en su contra fue el caso Caja-Fischel que tuvo comienzo el 3 de noviembre del 2008. Según este proceso judicial, el expresidente realizó contratos con una empresa finlandesa para la compra de equipo médico de segunda mano (Fiscalía Adjunta de Delitos Económicos, 2007). A pesar de que esta compra fue un trámite aprobado en un corto período de tiempo y la más grande inversión en equipo médico que ha realizado la institución, fue un mal negocio para la CCSS. Las condiciones de los instrumentos y del equipamiento estaban muy por debajo del precio al que fueron adquiridos. Por tal razón se le acusó a Calderón Fournier por realizar un acto desmesurado y perjudicial para la condición de la CCSS y se le dio una acusación por parte de la Fiscalía por crímenes de 
peculado y corrupción.

\section{Diversificación de riesgos en la protección social de la salud}

La diversificación del mercado en hospitales y clínicas ha generado que algunos de los usuarios dejen de acceder al régimen del Seguro Social para una atención básica y se trasladen a instituciones privadas, generando así una nueva dinámica de oferta y demanda en la cuantía de pacientes que la CCSS recibe. La insatisfacción causada por el debilitamiento de la institución generada a finales del siglo XX causó que constantemente menos usuarios vean factible mantener sus seguros como única vía de acceso a la medicina y opten por otras ofertas, ejecutando un efecto mariposa dentro de la institucionalidad médica. Una de las principales hipótesis suele tener como punto focal la desarticulación administrativa de la entidad pública a manos de actos de lucro y corrupción, mas yace también un alarmante índice de disgusto de los usuarios respecto al trato y efectividad de los tratamientos, a comparación con lo que se oferta en las ramas privadas. Este fenómeno puede dar fluidez al sistema de citas y listas de espera según una óptica estadística, dada la baja demanda en los centros de salud. No obstante, la excesiva burocratización dentro del esquema de operación administrativa articula vicios poco dinámicos que responden a intereses monetarios de los funcionarios públicos, los usuarios e incluso la participación gubernamental.

Fabio Durán y Fernando Herrero plantean un análisis de la medicina privada en el país en los últimos años de la década de los noventa. Dicho trabajo demostró que se ha cambiado la medicina estatal por la privada debido a muchos factores, entre ellos resaltan la falta de organización y el buen servicio. Mencionan los autores que la participación de la ciudadanía de ese momento era fundamental para la regulación de este sistema, por lo que por medio de la ley No 7.852, Desconcentración de los Hospitales y Clínicas de la Caja Costarricense de Seguro Social, se crearon las Juntas de Salud como entes auxiliares de los establecimientos y de las áreas de salud que actúan como proveedores de la CCSS, promulgadas en el 2000 (Durán y Herrero, 2001, p. 57). Estos permitieron la descentralización de los servicios, sin embargo, la falta de presupuesto empezó a generar deficiencias en los mismos y las personas con presupuesto para el costeo de medios alternativos al Seguro Social deciden acudir a los centros de salud privados para tener atención en intervalos de tiempo mucho más llamativos para el paciente. De manera lamentable, no se encuentra el dato estadístico de cuántos usuarios ingresan a esta modalidad, pero existe un mapeo general en perspectiva del acto, como mencionaron los autores en la siguiente cita:

"La "salida" de los grupos medios y altos del Sistema de Salud es una grave amenaza a su existencia, pues le resta legitimidad, genera presiones externas en contra del financiamiento solidario que aún 
La nueva orientación del régimen de salud en Costa Rica: un acercamiento al contexto de crisis institucional del Seguro Social tras el 75 aniversario de la promulgación de las garantías sociales

existe y debilita la "voz" al interior del sistema para promover altos estándares de calidad. Este es el centro de la llamada crisis del modelo de atención que se discute desde la década de los ochenta" (Durán y Herrero, 2001, p. 20).

Los autores señalaron que entre 1993 y 1998 las consultas en el sector público bajaron en $8 \%$, mientras que las consultas en la medicina privada crecieron un $20 \%$, estos se han caracterizado por presentar ingresos elevados en comparación con los demás sectores de la economía nacional. Sin embargo, como mencionan por Durán y Herrero (2001, p. 20), la CCSS abarcaba para el 2001 un $84 \%$ de las consultas y la casi totalidad de los casos hospitalarios. Es importante mencionar que para la época la mayor parte de la población asegurada eran personas en condiciones de pobreza y claro está que estas no utilizaban el sector privado de la medicina. Se especificó que en 1998 el 16\% de las consultas médicas fueron realizadas en clínicas y hospitales privados, los cuales atendieron consultas generales y especializadas.

En los últimos años, el sistema de salud costarricense apostó por una nueva estructura, más autónoma y virtual, para hacer frente al horizonte de competitividad contra el sector del capital privado. Gracias a los avances tecnológicos y las demandas de la nueva era, la empresa médica pública redireccionó su labor ante nuevos paradigmas acordes a la liberación económica. Sea desde idearios de gobiernos de turno o dinámicas mercantes a nivel internacional, dicha empresa vio una oportunidad para competir con los nuevos capitales privados en servicios hospitalarios, a costa de su naturaleza social. La Caja Costarricense del Seguro Social optó por eclipsar su antiguo monopolio de la oferta en salud, para dar una especialidad en la medicina de primera necesidad. Lo cual dio espacio a los hospitales privados para que incurrieran en las áreas de salud estética o auxiliar. No obstante, estas nuevas dinámicas entre los servicios de la empresa estatal y los sectores particulares, los cuales presentan beneficios como liberación burocrática y autonomía, también han generado una pérdida de fiadores.

A pesar de los obstáculos dentro de la institucionalidad, el Seguro Social ha logrado mantener como estandarte el principio de universalidad en su función, proporcionando el derecho de accesibilidad a la medicina a los diversos estratos de la sociedad, sean estos ciudadanos o no de la nación. Este juicio, digno del juramento hipocrático, tiene repercusiones para la estabilidad y solvencia económica del sistema, puesto que algunos abusos de esta esencia social concatenan efectos nocivos que también aportan al deterioro. Son varias las tangentes que obstruyen la fluidez del régimen de salud costarricense; un recuento bibliográfico señala a los gastos en productos farmacéuticos, la corrupción de los funcionarios desde los llamados "biombos" y la injerencia de los ingresos hospitalarios de emergencia y sus orígenes como las principales deficiencias ajenas a los ámbitos legislativos del sistema. 
El primero de los puntos, referido a la compra de los fármacos de la Caja, cuenta con una amplia explicación de gastos y fallas de aprovisionamiento en la materia. Su punto de partida, señala Jaramillo (2013, p. 13), germinó en la política de desconcentración de funciones de las Oficinas Centrales y su traslado hacia los hospitales y centros de salud cantonal, bajo el criterio de conocimiento de realidad y necesidad según cercanía al problema -solo los hospitales y las clínicas saben lo que realmente requieren-. Aunque en la lógica técnica sus fundamentos son apropiados, en la actualidad se observan las consecuencias de la entropía de compra y almacenamiento, dado que los programas de inventarios digitales y records de actas no corresponden con los conteos reales de las existencias físicas de los medicamentos (Jaramillo, 2013, p. 77). Ejemplo de ello son dos noticias en donde la prensa señaló a la CCSS como culpable de permitir la pérdida de dinero en drogas legales para tratamiento terapéutico. La primera citó el vencimiento de 880 toneladas de estos productos almacenados donde yacían hormonas y caros fármacos con un saldo de pérdida de $\mathbb{C} 740$ millones ( $L a$ Nación, 29 de setiembre del 2011, p. 6/A. citada por Jaramillo, 2013, p.79). La segunda apunta la pérdida de $\$ 300.000$ por reclamos contra proveedores de medicamentos que fueron archivados y no se les dio trámite antes de que los casos expiraran (Ávalos, 19 de julio de 2018).

Otra variable a considerar es la inversión y su evolución temporal dentro del marco en cuestión, donde Jaramillo (2013, p. 77) declaró que para el 2005 se gastaron $\mathbb{C} 36.351$ millones en compras de fármacos; para el 2010 dicha cifra se elevó a los $\mathbb{C} 80.902$ millones, mientras los datos del Informe de Ejecución Presupuestaria de Egresos de la CCSS indica que a junio del 2018 el presupuesto ordinario fue de $\mathbb{C} 149.835$ millones solo para la compra de productos farmacéuticos y medicinales (Gerencia Financiera CCSS, 2018). Si bien estas cifras tienen una naturaleza ascendente, existe una preocupación de parte de los especialistas en la salud y la comunidad académica respecto al mal uso que se le dan a estos medicamentos en manos de los pacientes y la presión por demanda de estos. Desde los últimos años, el despacho de medicamentos ha visto un aumento considerable dentro del sistema de la CCSS (ver gráfico 1), lo cual es una explicación por este aumento en el gasto de compra. 
La nueva orientación del régimen de salud en Costa Rica: un acercamiento al contexto de crisis institucional del Seguro Social tras el 75 aniversario de la promulgación de las garantías sociales

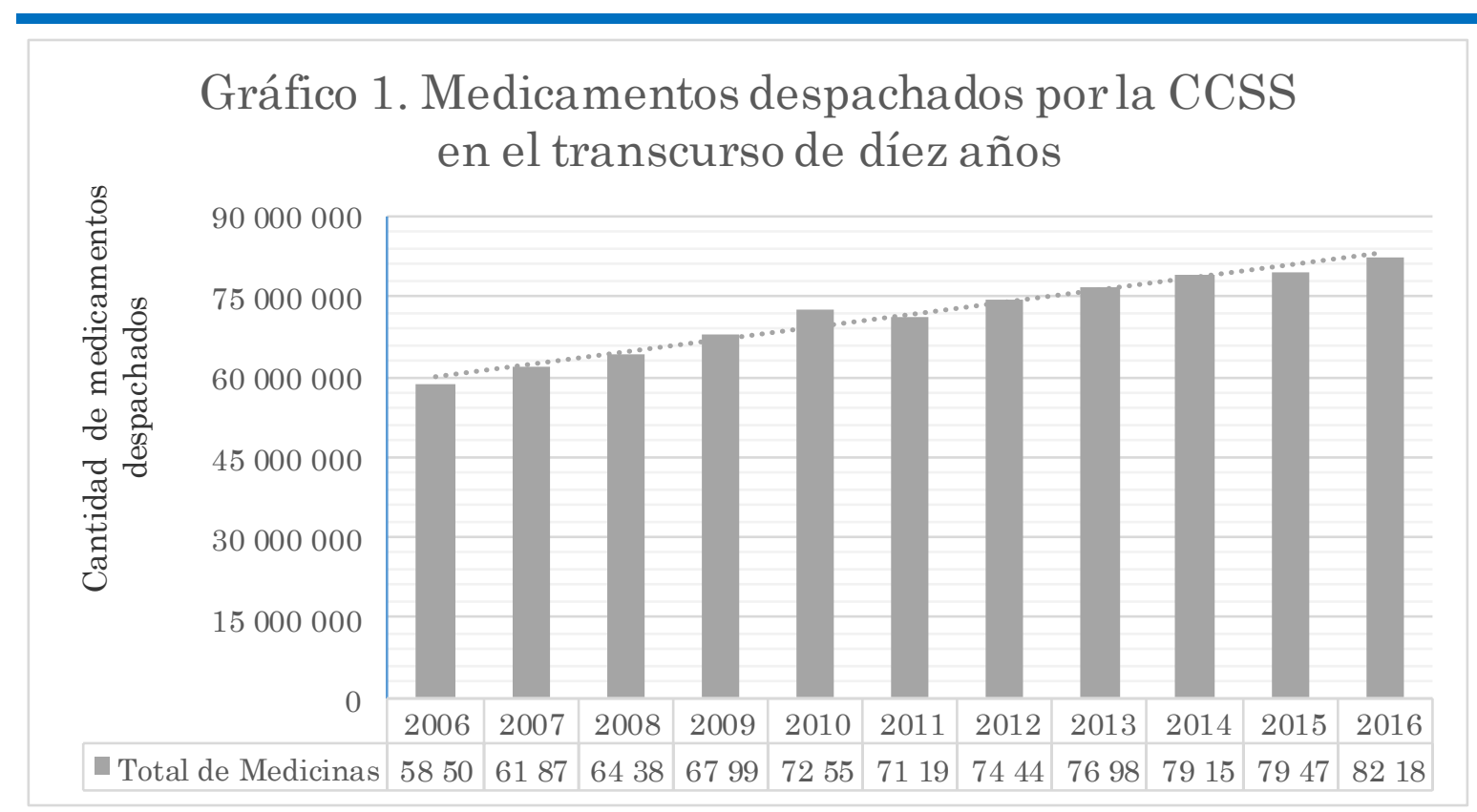

Fuente: Construcción propia a partir de los datos del Área de Estadística de Salud, CCSS., Anuario 2016, Cuadro No19.

El segundo obstáculo intrainstitucional corresponde a una nueva forma de corrupción ideada por algunos médicos y usuarios del Seguro Social, el denominado "biombo". Esta constituye una modificación en las listas de pacientes para que aquel "amigo" del médico sea atendido de inmediato o con preferencia a cambio de una remuneración económica al profesional en salud. Dicha práctica no solo incurre en la ilegalidad del trato en los hospitales y clínicas del país, puesto que utiliza los bienes de la institución pública para fines lucrativos, sino que también es un problema ético ante el cuerpo de profesionales que labora dentro del sistema de salud. Jaramillo (2013) explicó el dilema moral de esta forma de corrupción:

"El biombo es una corrupción de doble vía, el paciente paga porque le sale más barato que una clínica privada, y el médico que reciba una paga por ese servicio. Se escuchan rumores que determinado médico lleva a cabo esta infame práctica, pero ningún paciente -con algunas excepciones- acusa ante la dirección o las jefaturas al médico "biombero", pues también él se aprovecha, mediante un pago, de ser operado mucho antes; es por ello corresponsable del dolo" (p. 85).

De igual modo, este acto corrupto y el mal uso del servicio médico no solo trasciende en la consulta y las operaciones de los pacientes, puesto que en los últimos años muchos trabajadores han visto en esta mala praxis una vía para obtener incapacidades laborales. Ante esta modalidad particular de 
los engaños con licencias y permisos en salud, la CCSS y el MEP han optado por crear campañas de concientización y educación en materia de salud para reducir estos actos en la ciudadanía. En lo que respecta al sistema operativo, se pretende emplear una boleta digital por medio del Expediente Digital Único de Salud (EDUS), el cual posibilita hacer un enlace con el historial clínico del paciente y también evitar el "desvío" de documentos que propicia las incapacidades ficticias (Ávalos, 18 de abril del 2018).

Como último foco, está la problemática en los servicios de emergencia de los hospitales y los costos que implica para el sistema su ejecución. Para la logística del sector salud costarricense, el Servicio de Atención de Emergencias se encuentra en operación las veinticuatro horas del día, todos los días de la semana -a diferencia de otras áreas de atención, como la Consulta Externa que maneja horarios de oficina-. Este modelo vela por la atención de cualquier eventualidad que comprometa la atención del paciente y se procura su atención inmediata, sin tomar en cuenta su condición social o de asegurado.

No obstante, esta premisa de servicio sirve de portillo para muchos usuarios que no están asegurados. Donde posterior a su tratamiento y atención, se les envía a las oficinas de Validación de Derechos para ver su condición de asegurados o dar respuesta ante la eventualidad. Caso homólogo está en aquellos usuarios que acuden al Servicio de Emergencias para casos que no requieren un tratamiento de urgencia o su nivel de prioridad no es equiparable a otros individuos que también requieren el servicio. Esto solo genera una saturación de las salas y camas de este módulo, propiciando que los recursos médicos y el capital humano sea mal invertido. Para ilustrar este juicio se presenta el gráfico 2, el cual proyecta el total de atenciones anuales en los servicios de urgencias en los hospitales nacionales entre el año 2000 y el 2016. En el mismo se logra ver cómo existe una naturaleza ascendente en la demanda de este servicio en un lapso próximo de dos décadas y cómo es esperable que para el año 2020 la cantidad de atenciones duplique la cifra de principios del milenio. 
La nueva orientación del régimen de salud en Costa Rica: un acercamiento al contexto de crisis institucional del Seguro Social tras el 75 aniversario de la promulgación de las garantías sociales

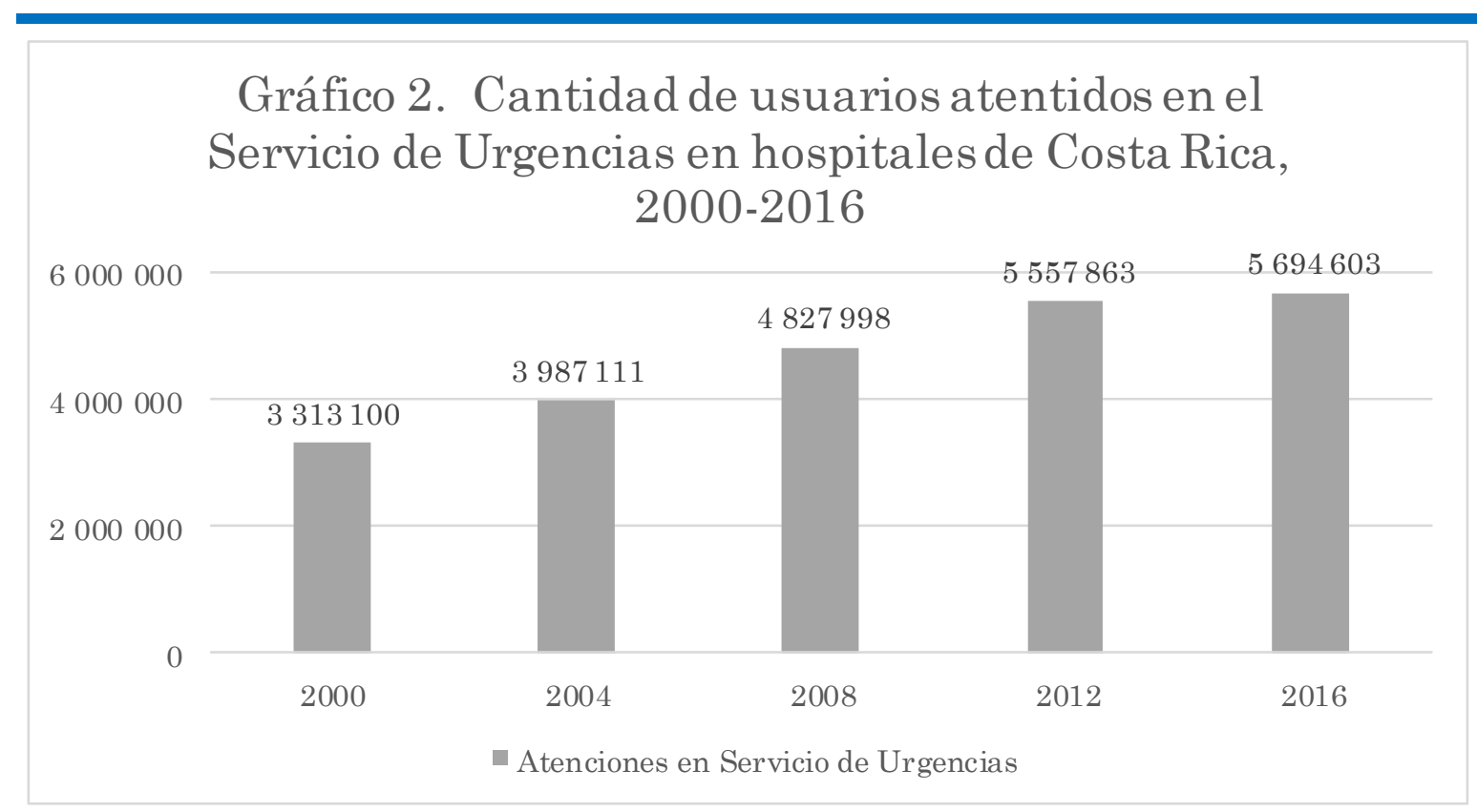

Fuente: Construcción propia a partir de los datos del Área de Estadística de Salud, CCSS., Anuario 2016, Cuadro No07.

La intención de este postulado crítico no es la descripción del sistema interno de la CCSS, pero cabe recalcar que en los casos donde no existan cuotas suficientes o ninguna dentro del historial de seguro del sujeto, el Estado y el resto de los asegurados costean el servicio de dicho paciente. Esto se justifica dentro del carácter social de la institución, dado que el Servicio de Emergencia de los hospitales lo utilizan todas las personas cuando así lo requieran. Dentro de esta discusión, suele existir en el imaginario colectivo una falsa premisa xenofóbica sobre el principio de universalidad de la CCSS, donde esta es la sentencia a la inoperancia, pues acepta a los extranjeros que no aportan al sistema de cuotas y seguros, mas son atendidos y costeados por la sociedad. Empero, al observar los datos brindados por el Área de Estadística en Salud de la CCSS, se observa que en el año 2016 existió un total de 354.575 egresos del sistema hospitalario nacional, de los cuales un $85,5 \%$ pertenecían al sistema de salud integral de la institución, mientras que los no asegurados correspondían a población nacional un $10,6 \%$ y solo un 3,3\% de extranjeros para dicho año (Área de Estadística de Salud, CCSS., 2016). Por lo que el imaginario de la inoperancia a causa de la población extranjera es falso, o no tiene un impacto tan grande, como sí lo puede potenciar el mal uso del Servicio de Emergencias y las alteraciones de las listas de pacientes, casos ya expuestos en párrafos anteriores. 


\section{Reflexiones respecto al tema}

Al hablar del sistema de salud del Estado de Costa Rica, suelen proyectarse dos perspectivas complejas. En una vertiente se suelen resaltar los aportes históricos que fueron consecuentes a los pactos del Estado benefactor y la bonanza social en el siglo XX. De igual forma, y con el mismo ímpetu, surge un repudio hacia el aparato público de salud por las falencias que la misma oferta a la población, la cual no cuenta con otra opción que capitalizar los fondos del seguro obligatorio para dar reproducción de males y vicios estructurales. La razón de que exista un debilitamiento del Seguro Social y los sistemas médicos públicos de Costa Rica no solo obedece a principios de corrupción y peculados gubernamentales, puesto que los usuarios tienen también una fuerte cuota de responsabilidad ante la situación actual del ámbito social. Como bien se argumenta en la intención social de la Caja Costarricense del Seguro Social, esta empresa ha de velar por la garantía y el derecho a una salud de calidad en todos sus niveles y, más allá de ser una compañía de servicios, es a su vez un ente jurídico con capacidades de respuesta ante las demandas de un mercado y la Res Publica.

Tras la llegada del 75 aniversario de la promulgación de las bases de la salud pública contemporánea costarricense, las garantías sociales, surge la necesidad de hacer crítica respecto al papel que ha tenido la sociedad en cuanto al régimen aquí expuesto. $\mathrm{Al}$ inicio de este artículo, se hace referencia a los principios teóricos que rigen el Seguro Social, el cual es explicado como un pacto entre la sociedad y el Estado para solventar las necesidades en diversos esquemas, mientras sea la misma sociedad la que potencie la extensión del sistema y su cobertura con afanes de productividad y bien común. A pesar de esto, es necesario tomar conciencia del menester del buen mantenimiento de dicha organización para propiciar una medicina igual para todos, en cantidad y calidad, con cobertura nacional y de tipo integral, como condición inalienable. Dentro de la cual su esencia no solo sea encapsulada en los pasillos de los hospitales, sino en los paradigmas mismos de la ciudadanía de Costa Rica y todos aquellos colectivos y actores sociales que no formen parte de la ciudadanía jurídica. Los esfuerzos alcanzados han sido de gran provecho, mas falta un largo trayecto por recorrer para lograr alcanzar los principios utópicos de la sociedad de bienestar ante las realidades del mercado neocapitalista.

\section{Referencias bibliográficas}

Área de Estadística de Salud, CCSS, (2016). Cuadro $N^{o}$ 06. Egresos hospitalarios por condición de aseguramiento, según red de servicios y establecimiento de salud. C.C.S.S., 2016. Recuperado de http://www.ccss.sa.cr/est_salud 
La nueva orientación del régimen de salud en Costa Rica: un acercamiento al contexto de crisis institucional del Seguro Social tras el 75 aniversario de la promulgación de las garantías sociales

Área de Estadística de Salud, CCSS, (2016). Cuadro $N^{o}$ 07. Atenciones de Urgencias y Consulta Externa, Según Personal que Atendió, en Instituciones de la CCSS y en el Servicio Alternativo (Empresas), 19802016. Recuperado de http://www.ccss.sa.cr/est_salud

Área de Estadística de Salud, CCSS, (2016). Cuadro $N^{o}$ 19. Medicamentos Despachado por Áreas de Atención, Empresas y Medicina Mixta, CCSS, 1980-2016. Recuperado de http://www.ccss.sa.cr/est_salud

Arias, R. y Muñoz, J. (2007). La reforma económica y su impacto social en Costa Rica durante el período de ajuste estructural: apuntes críticos para el análisis. Economía y Sociedad, 31-32, 9.

Ávalos, Á. (18 de abril, 2018). "Conozca la nueva arma que usará la CCSS para combatir engaños con incapacidades". La Nación. Recuperado de https://www.nacion.com/el-pais/salud/incapacidades-digitales-cierranportillo-a-abusos/MJRO6LZXQVHTZCK45CHKEI3TEE/story/

Ávalos, Á. (19 de julio, 2018). "CCSS pierde $\$ 300.000$ por reclamos contra proveedores que dejó engavetados". La Nación. Recuperado de https://www.nacion.com/el-pais/salud/ccss-pierde-300000-por-reclamo scontra/MUB47UCRV5G7VFWBVDBHP67WVM/story/

BINASS. (enero-agosto 1997). "Reseña histórica de las Instituciones del sector salud”. Hospitales de Costa Rica, 38-39, 12. Recuperado de http:// www.binasss.sa.cr/revistas/hcr/n38-391997/art7.pdf

Durán, F. y Herrero, F. (2001). El sector privado en el sistema de salud de Costa Rica. Chile: CEPAL.

Fiscalía Adjunta de Delitos Económicos. (2007). Expediente 04-005356-042-PE (17-04) (Acusación y Apertura de Juicio 04-005356-042-PE (17-04)). San José: Ministerio Público.

Gallardo, J. (2010). Salud en Costa Rica: incorporar el enfoque de capacidades para evaluar la equidad. Decimosexto Informe Estado de la Nación en Desarrollo Humano Sostenible (ed.), Programa Estado de la Nación (CONARE, Costa Rica).

Gerencia Financiera, CCSS. (2018). Programa 1 "Atención Integral de la Salud" Informe de Ejecución Presupuestaria de Egresos al 30 de junio del 2018. Recuperado de http://www.ccss.sa.cr/presupuesto?pagina=1 
Jaramillo-Antillón, J. (2013). La crisis en el Seguro Social de Costa Rica. El problema del régimen en salud. San José: EUCR.

Méndez, D. (2016). Visualización del diseño del Estado Costarricense en 180 años $y$ distribución del presupuesto. Recuperado de https://estadonacion.or.cr/historico-noticias/515-28-06-2016visualizacion-permite-analizar-diseno-del-estado-costarricense-en-180anos-y-distribucion-del-presupuesto

Olave, P. (1990). América Latina: entre la ortodoxia y la heterodoxia, recesión e inflación. Momento Económico, 49, 26. Recuperado de http://www.ru.iiec.unam.mx/2032/1/num49-articulo7_Olave.pdf

Programa Estado de la Nación. (2016). Visualización permite analizar diseño del Estado costarricense en 180 años y distribución del presupuesto. Recuperado de http://www.estadonacion.or.cr/historico-noticias/515-2806-2016-visualizacion-permite-analizar-diseno-del-estado-costarricenseen-180-anos-y-distribucion-del-presupuesto?highlight=WyJjYWphIl0=

Rodríguez, A. (2005). La reforma de salud en Costa Rica. Santiago, Chile: Naciones Unidas.

Rovira, J. (ed.), (1992). Enciclopedia de Costa Rica, su historia, tierra y gentes. Barcelona, España, OCEANO.

Vargas, L. (2015). La estrategia de liberalización económica. San José: EUCR. 